\title{
Avaliação e composição centesimal e as características físico- químicas da carne de ovinos
}

\author{
Braulio Crisanto Carvalho da Cruz ${ }^{1 *}$, Cristiane Leal dos Santos ${ }^{2}$, José Augusto Gomes \\ Azevedo $^{3}$, Denise Araújo da Silva ${ }^{4}$ \\ ${ }^{1}$ Prof. DSc. - Instituto Federal de Educação, Ciência e Tecnologia de Roraima - IFRR \\ ${ }^{2}$ Prof ${ }^{a}$ Dsc. - Universidade Estadual do Sudoeste da Bahia - UESB \\ ${ }^{3}$ Prof. DSc. - Universidade Estadual de Santa Cruz - UESC \\ ${ }^{4}$ Prof ${ }^{a}$. MSc. - Instituto Federal de Educação, Ciência e Tecnologia de Roraima - IFRR \\ *Autor para correspondência, E-mail: braulio.cruz@ifrr.edu.br
}

\begin{abstract}
RESUMO. A carne é uma fonte de proteína de elevado valor biológica, pela disponibilidade e digestibilidade de nutrientes essenciais. Apresenta vitaminas lipossolúveis (A, D, E e K), e hidrossolúveis do complexo B (tiamina, riboflavina, nicotinamida, piridoxina, ácido pantotênico, ácido fólico, niacina, cobalamina e biotina). Além disso, tem papel importante na nutrição como fonte de minerais e uma grande contribuição na absorção de selênio e cobre. Na carne vermelha, destacando-se a presença de ferro, fósforo, potássio, sódio, magnésio e zinco. O presente artigo aborda fatores como o tipo de músculo, idade do animal, nutrição, raça, condição sexual, manejo préabate e pós-abate dos animais, podem influenciar na composição centesimal (umidade, proteína, gordura e matéria mineral) e nas características físico-química da carne (cor, perda de peso por cocção, força de cisalhamento, pH e capacidade de retenção de água), tendo como objetivo nortear a cadeira produtiva da ovinocultura para uma homogeneidade na produção, com melhores características de carne, e, que atendam um mercado consumidor atual mais perceptível a qualidade de carne.
\end{abstract}

Palavras chave: carne, composição, ovinos

\section{Evaluation and proximate composition and as physical and chemical characteristics of meat from sheep}

\begin{abstract}
Meat is a source of high biological value protein, the availability and digestibility of essential nutrients. Displays soluble vitamins (A, D, E and K), and water soluble B-complex (thiamine, riboflavin, nicotinamide, pyridoxine, pantothenic acid, folic acid, niacin, biotin and cobalamin). In addition, an important role in nutrition as a source of minerals and a great contribution to the absorption of selenium and copper. In red meat, highlighting the presence of iron, phosphorus, potassium, sodium, magnesium and zinc. This article discusses factors as the type of muscle, the animal's age, nutrition, race, sexual condition, pre-slaughter management and post-slaughter, can influence the chemical composition (moisture, protein, fat and mineral matter) and in Physico-chemical characteristics of the meat (color, weight loss for cooking, shear strength, $\mathrm{pH}$, and water holding capacity), aiming to guide the production chain of the sheep industry for uniformity in production, with improved meat characteristics, and that meet a current consumer market more noticeable the quality of meat.
\end{abstract}

Keywords: meat, composition, sheep.

\section{Introdução}

A carne é uma fonte de proteína de elevado valor biológica, pela disponibilidade e digestibilidade de aminoácidos essenciais. Apresenta todas as vitaminas lipossolúveis (A, D, $\mathrm{E}$ e $\mathrm{K}$ ), as hidrossolúveis do complexo $\mathrm{B}$ 
(tiamina, riboflavina, nicotinamida, piridoxina, ácido pantotênico, ácido fólico, niacina, cobalamina e biotina) e um pouco de vitamina C(Berchielli et al., 2011). Além disso, tem papel importante na nutrição como fonte de minerais e uma grande contribuição na absorção de selênio e cobre. Na carne vermelha, destacando-se a presença de ferro, fósforo, potássio, sódio, magnésio e zinco (Luchiari Filho, 2000).

O perfil da carne consumida atualmente difere em relação aos parâmetros de qualidade, daquela tradicionalmente produzida há alguns anos. Se forem comparados os sistemas produtivos do passado vê-se claramente que houve melhoria na qualidade da carne ocasionada pelo melhoramento genético, que introduziu via seleção de linhagens, a diminuição da gordura das carcaças animais (hoje em torno de 60\% de carne na carcaça) (Rotta et al., 2009). Houve um grande avanço nutricional, onde as rações fornecidas aos animais são formuladas a partir de dietas calculadas para atender as exigências, garantir a saúde dos rebanhos e obterem-se ganhos superiores a $1.100 \mathrm{~g} /$ dia para suínos em fase de terminação e a conseguir frangos de corte com pesos superiores a $2,7 \mathrm{~kg}$ em 42 dias (Bellaver, 2003).

A carne, independentemente da espécie animal, deve corresponder às expectativas do consumidor no que se refere aos atributos de qualidade (Felício, 1997), por isso tem aumentado a produção de alimentos cárneos que atendam as exigências qualitativas do mercado consumidor. A qualidade da carne pode ser avaliada pelo $\mathrm{pH}$, cor, capacidade de retenção de água, maciez e perdas por cocção, e pelos aspectos sanitários e nutricionais (Guerrero et al., 2013). Tais características podem evidenciar carnes de melhor ou pior qualidade, e os resultados podem ser utilizados para determinar o preço dos produtos com distintas qualidades e serem direcionados para diferentes tipos de mercado (Pinheiro et al., 2010).

O mercado moderno de carnes é exigente quanto à qualidade sob os pontos de vista higiênico, sanitário e sensorial. Essa realidade impõe ao setor produtivo a necessidade de padronizar o produto oferecido e identificar os efeitos das técnicas de manejo, alimentação e melhoramento genético sobre as características de qualidade, embora os consumidores de diferentes países e regiões tenham demonstrado preferências específicas por distintos tipos de carcaças e carnes (Realini et al., 2013). As características da carcaça e da carne variam de acordo com o peso, a conformação, a quantidade e a distribuição de gordura. No entanto, para fazer frente a um mercado competitivo, é necessário que a carne ovina apresente parâmetros de qualidade desejáveis tanto quantitativos quanto qualitativos e que possa ser bem aproveitada quanto à forma de processamento, possibilitando sua maior valorização e contribuindo para a diversificação da indústria regional de derivados de carne (Sañudo et al., 1998).

Qualidade de carne para os pecuaristas se resume a "um nível ótimo de produção de acordo com os recursos disponíveis"; para os produtores se restringe ao "máximo rendimento de carcaça"; para os frigoríficos seria "um alto rendimento em cortes"; para o açougue pode-se afirmar que é "boa aparência e longa vida de prateleira"; e para o consumidor, em especial para o brasileiro, qualidade é "preço", muito embora alguma parte busque sanidade e aspectos organolépticos como cor, maciez e sabor (Hocquette et al., 2005). Segundo Felício (1997), a carne apresenta características físicas e organolépticas. Rotta et al. (2010) relatam que a carne ainda apresenta características nutricionais e higiênicas.

\section{Avaliação físico química da carne de ovinos}

A composição química da carne ovina varia com a categoria do animal e com a sua localização regional na carcaça (Kosulwat et al., 2003). A composição centesimal da carne sofre a influência de não somente um, mas de vários aspectos podendo-se citar a condição sexual, raça, idade e peso ao abate, condição nutricional, estratégia de manejo dentro outros (Guerrero et al., 2013).

Segundo Rotta et al. (2009), a grande variação existente na composição química da carne é devida a vários fatores, tais como o grupo muscular amostrado, grau de acabamento da carcaça e tipo de regime alimentar. Além disso, a preparação da amostra deve ser padronizada, principalmente em relação à manipulação na retirada das aponeuroses e gorduras externas, homogeneização e trituração para garantir a representatividade da mesma. Outro importante componente do tecido cárneo são os lipídios, compostos de origem biológica solúveis em solvente orgânico, com moléculas constituídas essencialmente de $\mathrm{C}, \mathrm{H}, \mathrm{O}$; em algumas classes 
P, N, S. São classificados como simples (ácidos graxos e alcoóis); compostos (fosfolipídios).

A carne é fonte de proteínas provenientes dos tecidos conjuntivos, miofibrilas e secundariamente do sarcoplasma (Babiker et al., 1990), apresentando no músculo cru 18 a $22 \%$ de proteína (Prache et al., 2011), o que dá importância à carne na dieta, pois as proteínas têm propriedades organolépticas de textura, podendo vir combinadas com lipídeos e carboidratos (Babiker et al., 1990). No entanto, Santos \& Pérez (2000) chamam a atenção para a definição de carne como um produto resultante de transformações contínuas do tecido muscular, possuindo quantidades variáveis de tecido conjuntivo e adiposo. Entretanto, não é válido o conceito de equivalência entre carne e tecido muscular, pois quando ingerimos carne, estamos consumindo quantidades de gordura e tecido conjuntivo, e ambos têm papel fundamental nas características sensoriais.

Segundo Warriss (1990) a qualidade da carne pode ser considerada como uma medida das características desejadas e valorizadas pelo consumidor; desta maneira, além dos aspectos sensoriais e tecnológicos, considerações éticas, bem como o impacto que estes provocam no meio ambiente, estão sendo incorporados para conceituar a qualidade da carne.

Para avaliação da qualidade da carne são levadas em consideração as propriedades da carne fresca, como pH, capacidade de retenção de água, cor e firmeza (características físicas), e as características da carne pronta para ser consumida, como maciez, odor, sabor e suculência (características organolépticas) (Webb et al., 2005; Webb \& O’Neill, 2008).

\section{Potencial de hidrogênio - Ph}

$\mathrm{O}$ pH exerce influência, direta ou indiretamente, sobre as diversas características de qualidade da carne como a cor, capacidade de retenção de água, maciez, suculência e sabor (Hopkins \& Fogarty, 1998). O pH final da carne está relacionado com a capacidade de retenção de água, coloração e textura da carne. Ocorrido o abate, a carne continua em processo bioquímico, no qual o condutor energético do músculo é transformado em glicogênio lático pela ação de várias enzimas e o pH da carne diminui devido à formação ácida (Felício, 1997). O animal recém abatido após um período de repouso, apresenta pH em torno de 6,9 a 7,2. A velocidade de queda do $\mathrm{pH}$, bem como o $\mathrm{pH}$ final da carne após 24-48 horas, é muito variável. Em suínos, o pH atinge valores de 5,3-5,7 após 24 horas post-mortem. $\mathrm{O} \mathrm{pH}$ da carne de frango deve apresentar $\mathrm{pH}$ final entre 5,7 e 5,9. Para bovinos, o pH cai para 5,5 5,9 após 24 horas post-mortem (Renerre, 1990). Passado 24 horas, se o pH da carne suína, de frango, bovina ou ovina estiver superior a 6,2, a carne irá reter grande quantidade de água, o que implica em curto tempo de conservação e coloração escura, fenômeno que caracteriza o processo DFD (dark, firm, dry - carne escura, dura e seca). Caso o pH se encontre abaixo de 5,8 em menos de 4 horas, teremos a carne PSE (pale, soft, exudative - pálida mole e exsudativa) caracterizado pela má retenção de água além do aspecto pálido e mole (Guerrero et al., 2013; Venturini et al., 2007). A condição PSE não constitui problema na carne bovina e ovina (Felício, 1997).

A capacidade de retenção de água é a capacidade que a carne tem de reter água durante o aquecimento, cortes, trituração ou prensagem (Pearce et al., 2011). A tendência de capacidade de retenção de água da carne pode ser averiguada medindo-se as perdas de peso por extravasamento de água extracelular, submetendo amostras de carne apenas à força da gravidade; aplicando-se pressão positiva ou negativa; de modo a forçar o extravasamento de água intra e extracelular, por métodos de centrifugação ou de compressão em papel de filtro; por aplicação de calor, método que serve para medir a liberação de água intra e extracelular de amostras submetidas ao cozimento, que desnatura as proteínas da carne (Herrero, 2008). Carnes com baixa capacidade de retenção de água são pouco firmes e as de alta capacidade de retenção de água tendem a ser muito firmes (Felício, 1997). O pH final é a causa das características de alta ou baixa capacidade de retenção de água (Pearce et al., 2011).

\section{Cor}

A coloração é um importante critério de avaliação da qualidade da carne pelos consumidores e é determinante na orientação da decisão no ato da compra (Guerrero et al., 2013; Mancini \& Hunt, 2005; Renerre, 2004). A cor da carne está relacionada com as fibras musculares, o pigmento mioglobina e a hemoglobina presente no sangue (Gao et al., 2014) e pode ser influenciada por diversos fatores tais como, o músculo, alimentação, $\mathrm{pH}$ e a concentração de 
gordura intramuscular (Sañudo et al., 2013). Os métodos laboratoriais avaliam a cor por meio da determinação da concentração de mioglobina por técnicas de espectrofotometria, sabendo que uma maior concentração de pigmento corresponde a um vermelho mais intenso na carne. Outro processo para medir a cor é o colorímetro que permite caracterizar a cor com base em parâmetros objetivos que podem ser determinados em vários sistemas, sendo o mais comum o sistema CIE (1986). Neste caso a cor é definida por três coordenadas: $\mathrm{L}^{*}$ - a refletância, que mede a quantidade de luz refletida; $a^{*}$ - que quantifica a cor no eixo vermelho/verde; e $b^{*}$ que quantifica a cor no eixo amarelo/azul. (Renerre, 2004). Segundo Miltenburg et al. (1992) quanto maiores os valores de $\mathrm{L}^{*}$, mais pálida é a carne, e quanto maiores valores de $\mathrm{a}^{*} \mathrm{e}$ $b^{*}$ mais vermelha e amarela, respectivamente.

A maciez é uma característica que pode ser percebida pelo consumidor, ou avaliada tecnicamente, em termos de consistência da carne sem osso (Sañudo \& Sierra, 1986). Os fatores que influenciam a firmeza da carne são: a quantidade e o tipo de fibras de colágeno, de gorduras subcutânea, intermuscular e intramuscular, e a capacidade de retenção de água (Felício, 1997; Jacob \& Pethick, 2014). A maciez é considerada a característica qualitativa da carne mais importante após a compra. A maciez da carne pode ser medida por meio subjetivo ou objetivo. O método subjetivo se utiliza de painel sensorial em que um grupo de pessoas treinadas classifica a carne em relação à maciez após ter provado as amostras (Guerrero, 2005). Pode ser definida como a facilidade de mastigar a carne com sensações distintas: uma inicial com facilidade de penetração e corte, uma mais prolongada com resistência à ruptura e uma final com sensação de resíduo (Koohmaraie et al., 1994). O método objetivo utiliza equipamento, como o texturômetro, que mede a força necessária para o cisalhamento de uma seção transversal de carne e, quanto maior a força dispensada, menor é a maciez apresentada pelo corte de carne (Shackelford et al., 1991; Wheeler et al., 1997). As características de maciez estão relacionadas com a capacidade de retenção de água, $\mathrm{pH}$, grau de gordura de cobertura e intramuscular e características do tecido conjuntivo e da fibra muscular (Zeola et al., 2004).

A cor é a característica mais importante para o consumidor no momento da compra e reflete o estado químico e o teor de mioglobina no músculo. $\mathrm{O}$ consumidor assumiu que a cor vermelha brilhante se relaciona a animais jovens com carne mais macia (Mancini \& Hunt, 2005). No entanto, a cor da carne é também uma questão cultural, já que, em países como a Espanha, o consumidor prefere a carne de coloração mais clara, enquanto outros países da Europa dão preferência à carne de coloração um pouco mais escura (Realini et al., 2013).

Normalmente carnes escuras são rejeitadas pelo comprador, que associa essas a carnes oriundas de animais mais maduros, portanto com carne dura. Entretanto, essa relação nem sempre é verdadeira, pois animais abatidos com pouca reserva de glicogênio não atingem valores de $\mathrm{pH}$ suficientemente baixos para produzir colorações normais, independente de sua idade e maciez (Jacob \& Pethick, 2014).

A cor do músculo é determinada pela quantidade de mioglobina e pelas proporções relativas desse pigmento, que pode ser encontrado na forma mioglobina reduzida $(\mathrm{Mb}$, cor púrpura), oximioglobina ( $\mathrm{MbO} 2$, cor vermelha) e metamioglobina (MetMb, cor marrom) (Mancini \& Hunt, 2005). Os varejistas consideram a cor da carne fator de importância primária na aceitação pelos consumidores (Verbeke et al., 2015) que preferem a cor vermelho- vivo (oximioglobina) da carne fresca, preterindo a cor marrom (metamioglobina). A cor da carne pode ser medida pelo método objetivo, utilizando-se colorímetro, que determina os componentes de cor L* (luminosidade), a* (teor de vermelho) e $b^{*}$ (teor de amarelo). Carnes com menor $\mathrm{L}^{*}$ e maior $\mathrm{a}^{*}$ apresentam cores mais vermelhas (Page et al., 2001). Em ovinos, são descritos valores médios de 31,36 a 38,0, para $\mathrm{L}^{*} ; 12,27$ a 18,01 , para a*; e 3,34 a 5,65, para b* (Bressan et al., 2001).

Mancini \& Hunt (2005) relatam que a intensidade da cor da carne é determinada pela concentração total e pela estrutura da mioglobina, que é afetada por fatores ante mortem, como espécie, sexo e idade do animal, e por fatores post mortem, como região anatômica, temperatura e $\mathrm{pH}$. Machos apresentam músculos com maior concentração de mioglobina que fêmeas, enquanto a concentração de mioglobina aumenta com a idade, de forma que cores mais rósea são indicativas de carnes provenientes de cordeiros machos (Simões \& Ricardo, 2000). Com relação ao pH e à ultra estrutura muscular, 
$\mathrm{pH}$ final baixo indica fibrilas musculares mais distantes (ponto isoelétrico das proteínas), com difração da luz, reduzindo a intensidade da cor (Silva Sobrinho et al., 2005). Por outro lado, as fibras musculares com $\mathrm{pH}$ final elevado $(6,2)$ ficam distendidas no meio cárneo, formando uma barreira à difusão de oxigênio e à absorção da luz. Portanto, segundo Silva Sobrinho et al. (2005), músculos com pH elevado não brilham após exposição da superfície ao oxigênio e inibem a formação da oximioglobina.

A cor da carne depende do $\mathrm{pH}$ e da velocidade das reações químicas post mortem (glicólise). Quando o animal é submetido a estresse no préabate, ocorre uma redução da quantidade de glicogênio muscular. Isso resulta em um $\mathrm{pH}$ elevado (acima de 6,0), o que torna mais ativas as citocromoxidases das mitocôndrias. Assim, um aumento no consumo de oxigênio pode aumentar a concentração de mioglobina desoxigenada, resultando em carnes de cor escura. Além disso, Carson et al. (1999) encontraram efeito dos genes Texel e Rouge nos valores de força de cisalhamento, perdas na cocção e cor da carne ovina.

Embora o consumidor avalie apenas os aspectos da qualidade visual da carne, como a cor do músculo e da proporção músculo/gordura, marmorização e firmeza do tecido muscular, a textura também deveria ser determinante na hora da compra. A textura visível é função do tamanho dos feixes de fibras que é determinado não somente pelo número de fibras, mas também pelo diâmetro destes (Maggioni et al., 2012).

\section{Textura}

A maciez é considerada, pelos consumidores, a característica mais importante da carne na análise sensorial (Safari et al., 2002). Podem-se encontrar variações nos valores de força de cisalhamento dentro da mesma espécie, pois existem diferenças entre as raças na musculosidade, idade de maturação do animal, além da ação enzimática, como a das calpastatinas (Rubensan et al., 1998).

É difícil medir a maciez da carne, um sistema complexo, tendo como principais estruturas fibras musculares e tecido conectivo, além de gordura entremeada. $\mathrm{O}$ aparelho de cisalhamento de Warner - Bratzler tem sido amplamente utilizado para avaliar a maciez da carne (Wheeler et al., 1997).
Watanabe et al. (1996) estudando a natureza da relação entre maciez e pH final (valores de 5,4 a 6,7) em ovinos de duas idades, observaram que a força de cisalhamento máxima foi encontrada em músculos ou amostras cujo $\mathrm{pH}$ foi 6,1 . A menor maciez em valores intermediários de $\mathrm{pH}$ final tem sido atribuída a efeitos diretos do $\mathrm{pH}$ sobre a atividade das enzimas proteolíticas que degradam a estrutura miofibrilar do músculo, mas causas não-enzimáticas também foram sugeridas. Menores comprimentos de sarcômero são reconhecidos como importante causa de dureza da carne (Herring et al., 1965) e parece que esses comprimentos tornam-se maiores quando o $\mathrm{pH}$ final atinge valores abaixo de 6,2 (Purchas \& Aungsupakorn, 1993).

De acordo com Silva Sobrinho (2001), a capacidade de retenção de água da carne consiste na habilidade de retenção durante a aplicação de força ou tratamento externa. As proteínas miofibrilares são os principais ligadores de água na carne (Pearce et al., 2011), sugerindo que mudanças na capacidade de retenção são causadas pelo espaçamento entre os filamentos. Segundo Zeola \& Silva Sobrinho (2001) características de maciez, como firmeza e sensações tácteis estão intimamente relacionadas à capacidade de retenção de água, ao $\mathrm{pH}$, ao estado de engorduramento e às características do tecido conjuntivo e da fibra muscular. Jacob \& Pethick (2014) consideraram o pH como o principal fator que afeta a capacidade de retenção de água, com capacidade de retenção mínima no ponto isoelétrico das proteínas da carne $(\mathrm{pH} 5,0$ $5,5)$.

Entre os fatores ante mortem, o genótipo está altamente correlacionado à maciez da carne (Rotta et al., 2009). Historicamente, a carne dos ovinos era identificada como dura, considerando que os mesmos eram criados em pastagens e abatidos mais velhos (raças leiteiras), se comparados às raças precoces da atualidade. Justifica-se também essa menor maciez pela correlação entre a idade de abate e o aumento do número de ligações cruzadas termoestáveis do colágeno, à menor deposição de gordura nas carcaças e ainda à escassez de gordura intramuscular (Silva Sobrinho et al., 2005). De acordo com Pardi et al. (1993) estes fatores favorecem o resfriamento mais rápido das massas musculares, provocando o encurtamento dos sarcômeros e o endurecimento da carne. 
A suculência da carne é um parâmetro obtido pela análise sensorial (Felício, 1997) e está associada à capacidade de retenção de água e ao teor de gordura intramuscular. Quando a carne é mastigada, a primeira impressão de suculência está relacionada à liberação de umidade e a impressão sustentada, à gordura intramuscular. (Henchion et al., 2014). Por sua vez, o aroma e sabor, também chamado de flavor da carne, são provenientes do aquecimento, decorrendo da transformação de substâncias lipossolúveis e hidrossolúveis e ainda a volatilização de alguns compostos indesejáveis na carne (Resconi et al., 2010; Resconi et al., 2012). A melhor maneira de avaliação é por meio de painel sensorial (Guerrero, 2005). A alteração do flavor da carne e o aparecimento de odores e sabores desagradáveis podem ocorrer em resultado da degradação dos lipídeos. Portanto, as carnes em que a gordura apresenta elevadas concentrações de ácidos graxos insaturados, embora não apresente necessariamente um flavor menos agradável, são mais susceptíveis de desenvolver flavores desagradáveis, quando as condições de conservação não forem as mais adequadas (Henchion et al., 2014; Resconi et al., 2012).

De acordo com Felício (1997) existe uma relação entre "qualidade exigida" e "características de qualidade" da carne. A "qualidade exigida" da cor vermelha de carne fresca, nem muito escura nem muito clara está ligada a "características de qualidade" como $\mathrm{pH}$ da carne; valor L (luminosidade). A "qualidade exigida" de capinha de gordura, carne macia (fácil de cortar) e suculenta estão relacionadas com as "características de qualidade" como espessura de gordura medida ou avaliada na carcaça (acabamento); pH, grau de marmorização da carne fresca, força de cisalhamento da carne assada e análise sensorial; grau de marmorização ou teor de lipídios intramusculares e análise sensorial, respectivamente (Guerrero et al., 2013; Sañudo et al., 2013).

\section{Composição centesimal da carne de ovinos}

Para avaliação da qualidade da carne são consideradas as propriedades da carne fresca, como $\mathrm{pH}$, capacidade de retenção de água, cor e firmeza (características físicas) e as características da carne pronta para ser consumida, como maciez, odor, sabor e suculência (características organolépticas) (Guerrero et al., 2013; Sañudo et al., 2013).

\section{Umidade}

A determinação da umidade é uma das medidas mais importantes e utilizadas na análise de alimentos, pois está relacionada com sua estabilidade, qualidade e composição, e pode afetar a estocagem, embalagem e processamento (Jiménez Colmenero, 1996). Tem grande influência na qualidade da carne, como na sua suculência, textura, cor e sabor, e nos processamentos que a mesma irá sofrer como resfriamento, congelamento, salga, cura, enlatamento, entre outros. Além disso, a água presente no músculo exerce influência sobre o rendimento da carcaça (perda de água da carcaça durante o resfriamento leva à perda de peso) e características sensoriais da carne (a água que fica retida no músculo interfere na maciez, suculência, aparência e coloração).

Segundo Zapata et al. (2001), os valores médios de umidade, proteína e cinzas na carne ovina do Nordeste brasileiro variam de 76,1 a $76,2 \%, \quad 19,2$ a $19,5 \%$ e 1,0 a $1,1 \%$, respectivamente, e de 2,0 a $2,4 \%$ para gordura, semelhantes aos valores apresentados por Ferrão (2006) que foram de $75 \%$ para umidade, $19 \%$ de proteína, $1,1 \%$ de matéria mineral e Zeola et al. (2004) de 75\% para umidade, 19\% para proteína e $1,1 \%$ de matéria mineral, diferindo apenas para gorduras $(4,4 \%$ e $4,0 \%)$.

\section{Perfil de ácidos graxos}

Estudos sugerem que o tipo e não a quantidade de ácidos graxos consumido está correlacionado à concentração de colesterol no sangue e ao risco de doenças coronarianas (Hu et al., 2001). No entanto, ainda não está claro o real efeito dos ácidos graxos na saúde humana, por exemplo, os ácidos graxos saturados, cuja ação aterogênica é questionada (German \& Dillard, 2004; Webb \& O'Neill, 2008).

Adicionalmente, o consumo de fontes ricas em ácidos graxos poliinsaturados (AGPI) ou alimentos que possuem maior razão de ácidos graxos poliinsaturados:saturados, também é desejável (Wood et al., 2003; Wood et al., 2004)., 2003). A carne ovina é caracterizada pela alta concentração de ácidos graxos saturados e pela baixa razão poliinsaturados:saturados (Sañudo et al., 2000). Entretanto, segundo Enser et al. (1998) a carne ovina é rica em ácido linolênico (C18:3) e possui baixa razão n-6:n-3 em comparação à carne bovina e suína. 
Rodrigues et al. (2010) avaliaram o perfil de ácidos graxos e composição química do músculo Longissimus dorsi de cordeiros Santa Inês alimentados com dietas contendo polpa cítrica, a polpa cítrica foi adicionada nos níveis de 23,7; 46,1 ; e $68,4 \%$ da matéria seca em substituição a 33, 67 e 100\% do milho, respectivamente. A substituição total do milho pela polpa cítrica promoveu aumento de $177 \%$ na concentração de ácido linolênico (C18:3), enquanto a substituição parcial resultou em aumento de $72 \%$ no ácido linoléico conjugado (C18:2 cis-9trans-11). Não houve alteração na concentração total de ácidos graxos saturados, monoinsaturados e poliinsaturados. Entretanto, a quantidade de gordura intramuscular do Longissimus dorsi diminuiu com o aumento de polpa cítrica na ração, sem alterar os teores de umidade, proteína e cinzas. Os autores concluem que a substituição do milho por polpa cítrica na ração modifica a quantidade e o perfil de lipídios do músculo Longissimus dorsi de cordeiros.

\section{Fatores que influenciam a composição da carne}

\section{Efeito o atordoamento}

Entre os inúmeros fatores que podem alterar a qualidade da carne, o estresse ante mortem é provavelmente o de maior interesse devido à sua influência na imagem do produto, bem como seu efeito sobre a qualidade da carne (Sañudo et al., 1998). Com relação a isso, a bibliografia atual indica que o tipo de atordoamento é um fator que afeta a qualidade da carne de cordeiro (Vergara \& Gallego, 2000; Vergara et al., 2005). Assim, estes autores concluíram que a carne de cordeiros atordoados eletricamente apresenta uma melhor qualidade do que de grupos não-atordoados.

Outros métodos tais como aqueles que utilizam gás (principalmente $\mathrm{CO} 2$ ), poderiam contribuir para a preservação da qualidade da carne (Gregory, 2005) diminuindo pontos hemorrágicos na carcaça, como consequência do aumento do ritmo cardíaco e frequência pressão sanguínea (Alvarez, 2002). No entanto, este último autor indicou que uma resposta variável em animais submetidos a diferentes concentrações de $\mathrm{CO}_{2}$ podem produzir resultados contraditórios, uma vez que Martoft et al. (2002) apontaram que a inalação de $\mathrm{CO}_{2}$ reduz a frequência cardíaca.

Linares et al. (2007) testaram três diferentes métodos de insensibilização, 1: cordeiros atordoados eletricamente a $110 \mathrm{~V}, 50 \mathrm{~Hz}$ durante 5 s (elétrodos aplicados em ambos os lados da cabeça, atrás das orelhas); 2:GSL, $(\mathrm{n}=10)$ : cordeiros surpreendeu usando gás $\mathrm{CO}_{2}$ em grupos de cinco na caixa, $90 \%$ de $\mathrm{CO}_{2}$ por 90 s na parte inferior do poço. Em seguida, os cordeiros foram abatidos usando o padrão procedimentos comerciais. O terceiro grupo foi atordoado utilizando pistola pneumática. Os autores concluíram que o método de atordoamento não afetou o valor final de $\mathrm{pH}$ e maciez da carne. Em relação à cor $\left(\mathrm{L}^{*}, \mathrm{a}^{*} \mathrm{e} \mathrm{b}^{*}\right)$ houve diferença significativa na carne de cordeiros utilizando o método de gás $\mathrm{CO}_{2}$, onde apresentou menores nos parâmetros de a e $b^{*}$. Os autores relatam ainda que a forma de atordoamento possa acelerar o envelhecimento da carne e favorecer alterações em alguns parâmetros de qualidade, como cor e perda de água.

\section{Efeito da nutrição}

As características nutricionais estão correlacionadas com a composição geral da carne e influenciadas pela porcentagem de água, valor biológico da proteína, teor e perfil de gordura, minerais e vitaminas. As características higiênicas estão relacionadas com a qualidade microbiológica da carne (Henchion et al., 2014).

A qualidade da carne é dependente da aplicação de tecnologias originadas no melhoramento genético, na saúde animal e na nutrição. Esses fatores, reconhecidamente afetam a qualidade e composição da carne dos animais (Guerrero et al., 2013; Moreira \& Prado, 2004; Rotta et al., 2010).

A nutrição influi no rendimento e na qualidade da carne, principalmente com relação aos tipos de ingredientes utilizados na fabricação das rações e aos níveis de energia, proteína e aminoácidos da dieta (Rotta et al., 2009), assim como os aditivos também têm sido utilizados para tal finalidade (Valero et al., 2014; Zawadski et al., 2010; Zawadzki et al., 2011a; Zawadzki et al., 2011b). Os diferentes sistemas de produção também interferem diretamente na qualidade da carne (Hocquette et al., 2011; Miranda-de la Lama et al., 2013).

Carvalho \& Medeiros (2010) avaliando a composição da carne de cordeiros mestiços Texel terminados em confinamento com dietas com diferentes níveis de energia $(1,49 ; 1,55 ; 1,62$; ou 1,68 Mcal de energia líquida/kg de matéria seca), segundo os autores A composição centesimal do 
Longissimus dorsi não foi influenciada pelo nível de energia da dieta com valores médios de umidade, proteína bruta, gordura e cinzas de 74,$5 ; 19,4 ; 5,2$ e 0,90 , respectivamente.

Monteiro et al. (2001) avaliaram a composição centesimal do músculo Longissimu sdorsi de cordeiros mestiços Texel $\times$ Corriedale criados em regime de pasto e abatidos aos 270 dias de idade e encontraram valores próximos aos deste experimento para umidade $(73,8 \%)$ e cinzas $(1,0 \%)$, entretanto, para os teores de proteína $(22,0 \%)$ e gordura $(3,2 \%)$. Klein Júnior et al. (2006) avaliaram a composição centesimal do músculo Longissimus lumborum de cordeiros mestiços com predominância da raça Ideal, não castrados, desmamados aos 70 dias de idade e mantidos em confinamento até o abate com peso vivo médio de $37 \mathrm{~kg}$, e verificaram valores médios similares $(71,9 \%$ de umidade; $20,6 \%$ de proteína, $5,5 \%$ de gordura e $1,1 \%$ de cinzas).

Avaliando as características de carcaça e da carne de caprinos Boer x Saanen confinados recebendo rações com casca do grão de soja em substituição ao milho, Hashimoto et al. (2007) constataram que a substituição do milho pela casca de soja nas rações promoveu aumento de 36,4 para $47,7 \mathrm{mg} / 100 \mathrm{~g}$ no teor de colesterol da carne caprina. De acordo com (Wood et al., 2008; Wood et al., 2003), o colesterol é uma substância complexa que apresenta inúmeras funções no organismo, porém, quando ocorrem problemas no seu metabolismo pode acarretar aumento em sua concentração no sangue e, conseqüentemente, doenças coronarianas como arterosclerose, além de causar hipertensão arterial, problemas de diabete mellitus e formação de cálculos biliares, no entanto as pessoas associaram esses problemas ao consumo de carne. $\mathrm{O}$ aumento indesejado do colesterol não está relacionado diretamente ao consumo de carne, mas ao tipo de gordura (monoinsaturada, poliinsaturada ou saturada) que está presente na dieta.

Zeola et al. (2004) estudaram a influência de diferentes níveis de concentrado sobre a qualidade da carne de cordeiros Morada Nova e verificou que não houve significância na musculosidade e a razão músculo:osso da perna dos cordeiros, entretanto influenciaram a razão músculo:gordura. Nas mensurações no músculo Longissimus dorsi, a espessura máxima de gordura foi influenciada pelos diferentes níveis de concentrado, sendo que a dieta com maior nível (60\%) apresentou maior valor, diferindo das dietas com 45 e $30 \%$ de concentrado. Tal fato corrobora que quanto maior o teor de concentrado na ração, maior a deposição de gordura na carcaça. Os crescentes níveis de concentrado afetaram a área de olho de lombo, sendo que a dieta com $60 \%$ de concentrado apresentou maior área. A composição química do músculo Semi membranosus variou no conteúdo de proteína no músculo, sendo maior no nível de $60 \%$ de concentrado, evidenciando que os níveis de concentrado influenciaram esta deposição. Estes autores ainda verificaram que os diferentes níveis de concentrado influenciaram a capacidade de retenção de água, com maiores valores nas dietas com 45 e $60 \%$ de concentrado. Clementino et al. (2007) relataram que o aumento do nível de concentrado na ração, provavelmente provocou mudança na fermentação ruminal ocasionando diferenciação no perfil dos ácidos graxos voláteis produzidos no rúmen $\mathrm{e}$ disponibilizando maior quantidade de ácido propiônico em relação ao ácido acético, que contribuiu para o aumento da energia disponível e favoreceu a maior porcentagem de gordura subcutânea e intermuscular.

Kessler et al. (2000) citado por Mendonça et al. (2008) explicaram que a quantidade de gordura depositada é diretamente proporcional à quantidade de energia disponível para síntese, portanto, a energia alimentar em excesso é bem correlacionado à deposição de lipídios na maioria dos animais.

O nível protéico da ração influencia diretamente a qualidade e composição da carcaça dos animais. Ortiz et al. (2005) estudaram a composição química do lombo de cordeiros alimentados e terminados com três níveis de proteína bruta em creep feeding e verificaram que à medida que se aumentou o nível de proteína na dieta houve aumento nos valores de cinzas, extrato etéreo e maciez da carne.

Madruga et al. (2005) avaliaram a qualidade da carne de cordeiros da raça Santa Inês terminados com diferentes dietas $\mathrm{T} 1=$ feno de capim d'água + concentrado, $\mathrm{T} 2=$ feno $\mathrm{de}$ restolho de abacaxi + concentrado, $\mathrm{T} 3=$ palma + mistura, $\mathrm{T} 4=$ silagem de milho + concentrado . Os autores concluem reatando que os tratamentos exerceram influência significativa sobre os teores de composição centesimal, cálcio, fósforo, colesterol, fosfolipídios, ácidos graxos saturados, poliinsaturados e sobre os parâmetros sensoriais da carne de ovinos Santa Inês. Os animais 
alimentados com palma forrageira (T3) produziram carnes com teores elevados de colesterol, ácidos graxos saturados, percentuais reduzidos de gorduras, ácidos graxos monoinsaturados e qualidade sensorial inferior à carne dos animais dos demais tratamentos. Os animais alimentados com volumosos contendo capim d'água (T1), restolho de abacaxi (T2) e silagem de milho (T4) apresentaram carne ovina de melhor qualidade, em função das baixas concentrações de colesterol e ácidos graxos saturados e do teor de ácidos graxos monoinsaturados, mesmo apresentando os maiores teores de lipídios.

Costa et al. (2011a) ao avaliarem a composição centesimal de ovinos Morada Nova alimentados com dietas contendo melão em substituição ao milho, segundo os autores na composição centesimal do músculo semi membranosus dos ovinos Morada Nova submetidos às dietas com diferentes níveis de frutos-refugo de melão, as porcentagens de umidade, matéria mineral, proteína e lipídios não foram influenciadas pelos níveis de substituição do milho por melão na dieta, com valores de 75,$2 ; 1,0 ; 18,5$ e 3,7. De acordo com Zeola et al. (2004), a composição centesimal da carne de cordeiros apresentam valores médios de $75 \%$ para a umidade, $19 \%$ para proteína, 4\% para gordura e $1,1 \%$ para as cinzas, porém esses valores podem variar de acordo como peso de abate, o estado de engorduramento, a idade do animal e a natureza da dieta. Segundo os mesmos autores, na avaliação dos atributos sensoriais da carne, nenhuma característica foi influenciada com adição de melão na dieta. Para os atributos de suculência, sabor e aceitação global foram obtidos os valores de 4,85; 4,78 e 5,15 pontos, respectivamente. Essas características sensoriais associadas à maciez determinam a sensação agradável ou desagradável que provoca a aceitação ou a recusa pelo consumidor.

\section{Efeito da genética}

Nos modernos sistemas de produção de carne ovina, buscam-se animais cruzados, com alto potencial genético para o ganho de peso e um sistema de terminação eficiente, para obtenção de maior quantidade de carne com qualidade, no menor espaço de tempo, com o custo de produção abaixo dos preços de comercialização, assegurando, dessa forma, o retorno econômico aos seus produtores (Macedo et al., 2006).
A carne de animais criados em diferentes sistemas de produção apresentam características qualitativas diferentes. Rotta et al. (2009) analisando diferentes formas de terminação de bovinos, verificaram espessura de gordura de cobertura de 3,4 $\mathrm{mm}$ em animais terminados em confinamento com silagem de sorgo ou milho e apenas $1,8 \mathrm{~mm}$ naqueles terminados à pastejo. Vestergaard et al. (2000) estudando as características quantitativas das carcaças de cordeiros Corriedale, Bergamácia-Corriedale e Hampshire Down-Corridale, terminados em pastagem ou em confinamento, constataram que animais confinados apresentaram carne com maior maciez suculência, possivelmente devido a maior quantidade de gordura intramuscular. De acordo com Morales et al. (2013), o marmoreio é uma característica importante, pois está relacionada às características sensoriais da carne. Moloney et al. (2013) relataram que animais terminados a pasto apresentam a gordura mais amarelada do que animais confinados, sendo que esta coloração mais intensa possui maior receptividade pelos consumidores. Animais confinados apresentam diferenças na coloração da gordura, dependendo do tipo de volumoso utilizado. French et al. (2000) observaram gordura mais amarelada para animais alimentados com silagem de gramínea, em relação aos alimentados com silagem de milho, fato explicado devido à maior presença de carotenóides nas gramíneas. No entanto, segundo estes autores, animais consumindo exclusivamente pastos de gramíneas apresentaram menores teores de ácidos graxos saturados na carne em relação aos animais que consumiam concentrado. Os teores de AGI aumentaram, tanto para os ácidos graxos monoinsaturados, quanto para os poliinsaturados.

Costa et al. (2011b) ao avaliarem a qualidade física e sensorial da carne de cordeiros de três grupos genéticos (Santa Inês, Dorper $\times$ Santa Inês e Sem Padrão Racial Definido) terminados em confinamento concluíram que carne de cordeiros SI e SRD possui menor dureza e maior suculência à carne de cordeiros Dorper $\times$ Santa Inês.O genótipo não influenciou o sabor, odor e a cor. Para os parâmetros físico-químicos a Perda de Peso por Cocção a Raça Santa Inês foi maior que os animais SRD. A perda de peso por cocção (PPC) caracteriza-se como importante parâmetro de avaliação da qualidade da carne. Associa-se ao rendimento no preparo para o consumo e influencia a suculência da carne. Não houve 
diferença entre os genótipos para força de cisalhamento $(\mathrm{Y}=5,2)$ e $\mathrm{pH}(\mathrm{Y}=5,5)$.

\section{Efeito da condição sexual}

Osório et al. (1999) comparando castrados e não castrados de cruzas Hampishire Down vs. Corriedale concluíram que não existe diferença quanto aos componentes do peso vivo, composição regional e tecidual da paleta e perna, contrariando o esperado que seria, animais castrados com maior percentual de gordura e inteiros com maior massa muscular, afirmando que não há vantagens em castrar cordeiros nessas condições com o objetivo de incremento de carne. Rota et al. (2006) chegaram à mesma conclusão avaliando a influência da castração e da idade de abate sobre as características subjetivas e instrumentais da carne de cordeiros Corriedale, dizendo ainda que, quanto à castração, esses animais podem ser comercializados numa mesma categoria comercial.

Klein Júnior et al. (2006) comparando castrados e não-castrados sob dois fotoperíodos, avaliaram a composição centesimal dos músculos dos cortes paleta e Longissimus lomborum, e observaram que as características que sofreram a influência da condição sexual foram: umidade, sendo menor nos castrados $(70,3 \%$ e $70,4 \%)$ que nos não-castrados $(72,1 \%$ e $72,0 \%)$ e extrato etéreo, sendo maior na carne dos animais castrados $(8,0 \%$ e $7 \%)$ do que na carne dos nãocastrados $(6,2 \%$ e $5,5 \%)$, e os castrados ainda apresentaram carne mais macia.

Ainda Klein Júnior et al. (2006) afirmaram que, embora as características mais desejadas, no que se refere ao teor de gordura, durante o desenvolvimento e na carcaça tenham sido verificados em animais não castrados, cordeiros castrados podem apresentar quantidade de gordura baixa na carcaça, concordando com Carvalho et al. (1999).

Para caprinos, Madruga et al. (2000) estudando o efeito da castração, sobre carne caprina de animais mestiços, concluiu que a castração influiu apenas nos teores de cálcio, sendo maior nos animais castrados, enquanto a maciez e qualidade total foram discretamente melhores para os não-castrados.

\section{Efeito da idade}

Segundo Carvalho et al. (2007), na produção de carne ovina, o cordeiro é potencialmente a categoria de melhores características da carcaça e, conseqüentemente, de maior aceitabilidade pelo consumidor. Schönfeldt et al. (1993) comparando ovinos e caprinos com diferentes idades, descreveram maior teor de umidade e menor teor de lipídeos para animais jovens em relação aos mais velhos e não encontrou diferença para proteína, concordando. Pinheiro et al. (2010) estudaram a qualidade de carne de ovelhas de descarte, abatidas em diferentes estágios fisiológicos com objetivo de encontrar o melhor estágio fisiológico para comercializar ovelhas de descarte. Foram realizados três tratamentos, sendo estes. $\mathrm{T} 1=$ ovelhas que permaneceram por 60 dias em lactação com seus respectivos cordeiros e abatidas um dia após o desmame das crias; $\mathrm{T} 2=$ ovelhas que permaneceram por 60 dias em lactação com seus respectivos cordeiros e mais um período aproximado de 30 dias sem os cordeiros e posteriormente abatido; e T3 = ovelhas que não pariram durante $\mathrm{o}$ ano. Para força de cisalhamento observou-se que o tratamento T1 foi maior que os demais, apresentando uma carne menos macia. Não houve diferença entre a cor da gordura subcutânea do Longissimus lomborum; no entanto, o tratamento $\mathrm{T} 1$ apresentou maior luminosidade que os demais tratamentos.

Fatores diversos, como o sexo, a raça, a idade de abate e o peso ao abate, entre outros, podem afetar a qualidade da carne ovina. Sañudo et al. (1997) reportaram que, em geral, as fêmeas de cordeiros depositam mais gordura distribuída nas regiões lombares e ventrais da carcaça em comparação aos machos. Rotta et al. (2009) relataram que, dentro de uma mesma raça, o efeito do sexo sobre a composição tecidual pode acentuar-se com o peso de abate e verificaram que as fêmeas depositaram mais tecido adiposo que os machos. Estes autores também verificaram efeito do sexo sobre a proporção de osso da carcaça de cordeiros, de modo que os machos apresentaram maior proporção de ossos em comparação às fêmeas.

Madruga et al. (2005) ao avaliarem o efeito do genótipo e do sexo sobre a composição química e o perfil de ácidos graxos da carne de cordeiros. Concluíram que os parâmetros raça e sexo não influenciaram a composição centesimal da carne de cordeiro. No entanto, as concentrações de fósforo, ferro e cálcio diferiram na carne de Santa Inês machos e fêmeas, de modo que, juntamente com os percentuais totais de ácidos graxos mono e poliinsaturados, as concentrações desses 
minerais foram significativamente influenciadas pelos cruzamentos. Qualitativamente, o perfil de ácidos graxos de mestiços SI-D apresentou melhor valor nutricional, comprovado pela maior concentração de ácidos graxos poliinsaturados e pelas relações maior de AGPI/AGS e menor de w6:w3.

\section{Conclusão}

O consumidor esta cada vez mais atento a fatores que envolvem a qualidade dos produtos consumidos. A avaliação de características da carne de ovinos ajuda o produtor a se nortear na produção de animais de corte com melhores atributos químicos, físicos e sensoriais.

\section{Referências Bibliográficas}

Alvarez, D. (2002). Influencia de las condiciones ante-mortem y la tecnología del sacrificio sobre la calidad de la carne porcina. Doctoral Thesis, Spain, pp. 334.

Babiker, S. A., El Khider, I. A. \& Shafie, S. A. (1990). Chemical composition and quality attributes of goat meat and lamb. Meat Science, 28: 273-277.

Bellaver, C. (2003). Práticas zootécnicas relacionadas com a qualidade da carne. 20 Simpósio de Ciência dos Alimentos da Universidade Federal de Santa Catarina. Concórdia - SC, 2003. Disponível em: <www.agencia.cnptia.embrapa.br/Reposit orio/praticas_zootecnicas_relacionadas_co m_qualidade_carne_000fz763ktz02wx5ok 0cpoo6avywswtl.pdf>. Acesso em: 12/01/2016.

Berchielli, T. T., Pires, A. V. \& Oliveira, S. G. (2011). Nutrição de Ruminantes. 2th ed. FUNEP, Jaboticabal, Brazil.

Bressan, M. C., Prado, O. V., Pérez, J. R. O., Lemos, A. \& Bonagurio, S. (2001). Efeito do peso ao abate de cordeiros Santa Inês e Bergamácia sobre as características físicoquímicas da carne. Ciência e Tecnologia de Alimentos 21: 293-303.

Carson, A. F., Moss, B. W., Steen, R. W. J. \& Kilpatrick, D. J. (1999). Effects of the percentage of Texel or Rouge de l'Ouest genes in lambs on carcass characteristics and meat quality. Animal Science, 69: 81-92.
Carvalho, S., BrochierII, M. A., Pivato, J., Kieling, R. \& Cánovas Teixeira, R. C. (2007). Ganho de peso, características da carcaça e componentes não-carcaça de cordeiros da raça Texel terminados em diferentes sistemas alimentares. Ciencia Rural 37.

Carvalho, S., \& Medeiros, L. M. (2010). Características de carcaça e composição da carne de cordeiros terminados em confinamento com dietas com diferentes níveis de energia. Revista. Brasileira de Zootecnia, 39: 1295-1302.

Carvalho, S., Pires, C. C., Peres, J. R. R., Zeppenfeld, C. \& Weiss, A. (1999). Desempenho de cordeiros machos inteiros, machos castrados e fêmeas, alimentados em confinamento. Ciencia Rural, 29: 129-133.

CIE. (1986). Colorimetry Commission Internationale de l'Eclairage. Commission Internationale de l'Eclairage, Vienna.

Clementino, R. H., W. H. Sousa, A. N. Medeiros, M. G. G. Cunha, S. Gonzaga Neto, F. F. R. Carvalho et al. (2007). Influência dos níveis de concentrado sobre os cortes comerciais, os constituintes não-carcaça e os componentes da perna de cordeiros confinados. Revista Brasileira de Zootecnia, 36.

Costa, R. G., Lima, C., Medeiros, A., Lima, G. Marques, C. A. T. \& Queiroga, R. (2011a). Composição centesimal e análise sensorial da carne de ovinos Morada Nova alimentados com dietas contendo melão em substituição ao milho. Revista Brasileira de Zootecnia, 40: 2799-2804.

Costa, R. G., Santos, N., Sousa W., Queiroga, R., Azevedo, P. \& Cartaxo, F. (2011b). Qualidade física e sensorial da carne de cordeiros de três genótipos alimentados com rações formuladas com duas relações volumoso: concentrado. Revista Brasileira de Zootecnia, 40: 17811787.

Enser, M., K. G. Hallett, B. Hewett, G. A. J. Fursey, J. D. Wood, \& G. Harrington. (1998). The polyunsaturated fatty acid composition of beef and lamb liver. Meat Science, 49: 321327.

Felício, P. E. (1997). Fatores ante e post mortem que influenciam na qualidade da carne bovina. Produção de Novilhos de corte 1 ed. Piracicaba: FEALQ, v. Único, 79-97. 
Ferrão, S. P. B. (2006). Características morfométricas, sensoriais e qualitativas da carne de cordeiros, Universidade Federal de Lavras, Lavras.

French, P., O'Riordan, E. G., Monahan, F. J., Caffrey, P. J., Vidal, M. \& Mooney. M. T. (2000). Meat quality of steers finished on autumn grass, grass silage or concentratebased diets. Meat Science, 56: 173-180.

Gao, X., Wang, Z., Miao, J., Xie, L., Dai, Y. \& $\mathrm{Li}, \quad \mathrm{X}$. (2014). Influence of different production strategies on the stability of color, oxygen consumption and metmyoglobin reducing activity of meat from Ningxia Tan sheep. Meat Science, 96: 769-774.

German, J. B. \& Dillard, C. J. (2004). Saturated fats: what dietary intake? The American Journal of Clinical Nutrition, 80: 550-559.

Gregory, N. G. (2005). Recent concerns about stunning and slaughter. Meat Science, 70: 481-491.

Guerrero, A., Valero, M. V., Campo, M. M. \& Sañudo, C. (2013). Some factors that affect ruminant meat quality: from the farm to the fork. Review. Acta Scientiarum Animal Sciences, 35: 335-347.

Guerrero, L. (2005). Panel entrenado. In: V. Cañeque \& C. Sañudo (eds.) Estandarización de las metodologías para evaluar la calidad del producto (animal vivo, canal, carne $\mathrm{y}$ grasa) en los rumiantes No. 1. p 397-408. INIA, Zaragoza.

Hashimoto, J. H., Alcalde, C. R., Silva, K. T., Macedo, F. d. A. F. d., Mexia, A. A., Santello, G. A., Martins, E. N. \& Matsushita, M. (2007). Características de carcaça e da carne de caprinos Boer $\mathrm{x}$ Saanen confinados recebendo rações com casca do grão de soja em substituição ao milho. Revista Brasileira de Zootecnia, 36: 165-173.

Henchion, M., McCarthy, M., Resconi, V. C. \& Troy, D. (2014). Meat Consumption: Trends and Quality Matters. Meat Science, 98: 561568.

Herrero, A. M. (2008). Raman spectroscopy a promising technique for quality assessment of meat and fish: A review. Food Chemistry, 107: 1642-1651.

Herring, H. K., Cassens, R. G. \& Rriskey, E. J. (1965). Further studies on bovine muscle tenderness as influenced by carcass position, sarcomere length, and fiber diameter. Journal Food Science, 30: 1049-1054.

Hocquette, J. F., Legrand, I., Jurie, C., Pethick, D. W. \& Micol, D. (2011). Perception in France of the Australian system for the prediction of beef quality (Meat Standards Australia) with perspectives for the European beef sector. Animal Production Science, 51: 30-36.

Hocquette, J. F., Richardson, R. I., Prache, S., Medale, F., Duffy, G. \& Scollan, N. D. (2005). The future trends for research on quality and safety of animal products. Italian. Journal Animal Science, 4: 49-72.

Hopkins, D. L., \& Fogarty, N. M. (1998). Diverse lamb genotypes-2. Meat $\mathrm{pH}$, colour and tenderness. Meat Science, 49: 477-488.

Hu, F. B., Manson, J. E. \& Willett, W. C. (2001). Types of dietary fat and risk of coronary heart disease: a critical review. J. Am. Coll. Nutr. 20: 5-19.

Jacob, R. H. \& Pethick, D. W. (2014). Animal factors affecting the meat quality of Australian lamb meat. Meat Science, 96: 1120-1123.

Jiménez Colmenero, F. (1996). Technologies for developing low-fat meat products. Trends in Food Science and Technology 7: 41-48.

Klein Júnior, M. H., Siqueira, E. R. \& Roça, R. O. (2006). Qualidade da carne de cordeiros castrados e não-castrados confinados sob dois fotoperíodos. Revista Brasileira de Zootecnia, 35: 1872-1879.

Koohmaraie, M., Wheeler, T. \& Shackelford, S. (1994). Beef tenderness: regulation and prediction. Nebraska: US Meat Animal Research Center.

Kosulwat, S., Greenfield, H. \& James, J. (2003). Lipid composition of Australian retail lamb cuts with differing carcass classification characteristics. Meat Science, 65: 1413-1420.

Linares, M. B., Bórnez, R. \& Vergara, H. (2007). Effect of different stunning systems on meat quality of light lamb. Meat Science, 76: 675681.

Luchiari Filho, A. (2000). Pecuária da carne bovina. 1 ed. LinBife, São Paulo. 
Macedo, F. A. F., Siqueira, E. R., Martins, E. N.F., Macedo, G., Macedo, V. P. \& Yamamoto, S. M. (2006). Características quantitativas das carcaças de cordeiros Corriedale, Bergamácia-Corriedale e Hampshire Down-Corriedale, terminados em pastagem ou em confinamento. Acta Scientiarum Animal Sciences, 28: 339-344.

Madruga, M. S., Arruda, S. G. B., Narain, N. \& Souza, J. G. (2000). Castration and slaughter age effects on panel assessment and aroma compounds of the "mestiço" goat meat. Meat Science, 56: 117-125.

Madruga, M. S., Sousa, W. H., Rosales, M. D., Cunha, M. G. G. \& Ramos, J. L. d. F. (2005). Qualidade da carne de cordeiros Santa Inês terminados com diferentes dietas. Revista Brasileira de Zootecnia, 34: 309-315.

Maggioni, D., Prado, I. N., Zawadzki, F., Valero, M. V., Marques, J. A., Bridi A. M., Moletta, J. L. \& Abrahão, J. J. S. (2012). Grupos genéticos e graus de acabamento sobre qualidade da carne de bovinos. Semina: Ciências Agrarias, 33: 391-402.

Mancini, R. A., \& Hunt, M. C. (2005). Current research in meat color. Meat Science, 71: 100121.

Martoft, L., Lomholt, L., Kolthoff, C., Rodriguez, B., Jensen, E., Jørgensen, P. F., Pedersen, H.D. \& Forslid A. (2002). Effects of $\mathrm{CO} 2$ anaesthesia on central nervous system activity in swine. Lab. Anim. 36: 115-126.

Mendonça, G., Osório, J. C. S., Osório, M. T. M., Silveira, I. D. B., Gonçalves, M. \& A. Rocha. (2008). Época de nascimento sobre a composição regional e tecidual da carcaça de cordeiros da raça Texel. Revista Brasileira de Zootecnia, 37: 1072-1078.

Miltenburg, G. A., Wensing, T., Smulders, F. J. \& Breukink, H. J. (1992). Relationship between blood hemoglobin, plasma and tissue iron, muscle heme pigment, and carcass color of veal. J. Anim. Sci. 70: 2766-2772.

Miranda-de la Lama, G. C., Pascual-Alonso, M., Guerrero, A., Alberti, P., Alierta, S., Sans, P., et al. (2013). Influence of social dominance on production, welfare and the quality of meat from beef bulls. Meat Science, 94: 432-437.

Moloney, A. P., Mooney, M. T., Kerry, J. P., Stanton, C. \& O'Kiely, P. (2013). Colour of fat, and colour, fatty acid composition and sensory characteristics of muscle from heifers offered alternative forages to grass silage in a finishing ration. Meat Science, 95: 608-615.

Morales, R., Aguiar, A. P. S., Subiabre, I. \& Realini, C. E. (2013). Beef acceptability and consumer expectations associated with production systems and marbling. Food Quality and Preference 29: 166-173.

Moreira, F. B., \& Prado, I. N. (2004). Uso de ácidos ômega 3 e ômega 6 sobre a produção e qualidade da carne e leite de ruminantes. In: I. N. Prado (ed.) Conceitos sobre a produção com qualidade de carne e leite No. 1. p 203222. Eduem, Maringá, Paraná, Brasil.

Ortiz, J. S., Costa, C., Garcia, C. A., \& Silveira, L. V. A. (2005). Medidas objetivas das carcaças e composição química do lombo de cordeiros alimentados e terminados com três níveis de proteína bruta em creep feeding. Revista Brasileira de Zootecnia, 34: 23822389.

Osório, J. C. S., Conceição Jardim, P. O., Pimentel, M. A., Pouey, J.M. Osório, T. M., Lüder W. E. \& Borba, M. F. (1999). Produção de carne entre cordeiros castrados e não castrados: 1. Cruzas Hampshire Down X Corriedale. Ciencia. Rural, 29: 135-138.

Page, J. K., Wulf, D. M. \& Schwotzer, T. R. (2001). A survey of beef muscle color and $\mathrm{pH}$. Journal Animal Science 79: 678-687.

Pardi, M. C., dos Santos, I. F., de Souza, E. R. \& Pardi, H. S. (1993). Ciência, higiene e tecnologia da carne. CEGRAF-UFG; Niterói: EDUFF.

Pearce, K. L., Rosenvold, K., Andersen, H. J. \& Hopkins, D. L. (2011). Water distribution and mobility in meat during the conversion of muscle to meat and ageing and the impacts on fresh meat quality attributes - A review. Meat Science, 89: 111-124.

Pinheiro, R. S. B., Jorge, A. M. Souza, H. B. A. \& Boiago, M. M. (2010). Coloração da gordura e qualidade da carne de ovelhas de descarte abatidas em distintos estágios fisiológicos. Arq. Bras. Med. Vet. Zootec. 62: 468-474.

Prache, S., Gatellier, P., Thomas, A., Picard, B., \& Bauchart, D. (2011). Comparison of meat and carcass quality in organically reared and conventionally reared pasture-fed lambs. Animal 5: 2001-2009. 
Purchas, R. W. \& Aungsupakorn, R. (1993). Further investigations into the relationship between ultimate $\mathrm{pH}$ and tenderness for beef samples from bulls and steers. Meat Science, 34: 163-178.

Realini, C. E., Font i Furnols, M., Sañudo, C., Montossi, F., Oliver, M. A. \& Guerrero L. (2013). Spanish, French and British consumers' acceptability of Uruguayan beef, and consumers' beef choice associated with country of origin, finishing diet and meat price. Meat Science, 95: 14-21.

Renerre, M. (2004). La couleur de la viande et sa mesure. INRA 1: 63-68.

Renerre, M. T. (1990). Factors involved in the discoloration of beef meat. Int. Journal Food Science, Technol. 25: 613-630.

Resconi, V. C., Campo, M. M., Montossi, F., Ferreira, V., Sañudo, C. \& Escudero, A. (2010). Relationship between odour-active compounds and flavour perception in meat from lambs fed different diets. Meat Science, 85: 700-706.

Resconi, V. C., Escudero, A., Beltrán, J. A., Olleta, J. L., Sañudo, C. \& Campo, M. M. (2012). Color, lipid oxidation, sensory quality, and aroma compounds of beef steaks displayed under different levels of oxygen in a modified atmosphere package. Journal Food Science, 71: S10-S18.

Rodrigues, G. H., Susin, I., Pires, A. V., Alencar, S. M., Mendes, C. Q. \& Gentil. R. S. (2010). Perfil de ácidos graxos e composição química do músculo longissimus dorsi de cordeiros alimentados com dietas contendo polpa cítrica. Revista Brasileira de Zootecnia, 39: 1346-1352.

Rota, E. L., Osório, M. T. M., Osório, J. C. S., Oliveira, M. M., Wiegand, M. M., Mendonça G., Esteves, R. M. \& Gonçalves, M. (2006). Influência da castração e da idade de abate sobre as características subjetivas e instrumentais da carne de cordeiros Corriedale. Revista Brasileira de Zootecnia, 35: 2397-2405.

Rotta, P. P., Prado, I. N. \& R. M. Prado. (2010). Desempenho, qualidade da carcaça e da carne em bovinos. In: I. N. Prado (ed.) Produção de bovinos de corte e qualidade da carne No. 1. p 191-242. Eduem, Maringá, Paraná, Brasil.
Rotta, P. P., Prado, R. M., Prado, I. N., Valero, M. V., Visentainer, J. V. \& Silva, R. R. (2009). The effects of genetic groups, nutrition, finishing systems and gender of Brazilian cattle on carcass characteristics and beef composition and appearance: a review. Asian-Australas. J. Anim. Sci. 22: 1718-1734.

Rubensan, J. M., Felício, P. E. \& Termignoni, C. (1998). Influência do genótipo Bos indicus na atividade de calpastatina e na textura da carne de novilhos abatidos no sul do Brasil. Ciência e Tecnologia de Alimentos 18: 1-6.

Safari, E., Channon, H. A., Hopkins, D. L., Hall, D. G. \& Van de Vem, R. (2002). A national audit of retail lamb loin quality in Australia. Meat Science, 61: 267-273.

Santos, C. \& Pérez, J. (2000). Cortes comerciais de cordeiros Santa Inês. Encontro Mineiro de Ovinocultura 1: 149-168.

Sañudo, C., Campo, M. M., Sierra, I., María, G. A., Olleta, J. L. \& Santolaria. P. (1997). Breed effect on carcase and meat quality of suckling lambs. Meat Science, 46: 357-365.

Sañudo, C., Enser, M. E., Campo, M. M., Nute, G. R., María, G., Sierra I. \& Wood, J. D. (2000). Fatty acid composition and sensory characteristics of lamb carcasses from Britain and Spain. Meat Science, 54: 339-346.

Sañudo, C., Muela, E. \& Campo, M. M. (2013). Key factors involved in lamb quality from farm to fork in europe. Journal of Integrative Agriculture 12: 1919-1930.

Sañudo, C., Sanchez, A. \& Alfonso, M. (1998). Small ruminant production systems and factors affecting lamb meat quality. Meat Science, 49, Supplement 1: S29-S64.

Sañudo, C. \& Sierra. A. I. (1986). Calidad de la canal en la especie ovina. In: Ovino. p 127153.

Schönfeldt, H. C., Naudé, R. T., Bok, W., van Heerden, S. M., Sowden, L. \& Boshoff, E. (1993). Cooking- and juiciness-related quality characteristics of goat and sheep meat. Meat Science, 34: 381-394.

Shackelford, S. D., Morgan, J. B., Cross, H. R.,\& Savell, J. W. (1991). Idedntification of threshold levels for Warner-Bratzler shear force in beef top poils steakes. Journal of Muscle Foods 2: 289-296. 
Silva Sobrinho, A. (2001). Aspectos quantitativos e qualitativos da produção de carne ovina. Reunião Anual da Sociedade Brasileira de Zootecnia 38: 425-446.

Silva Sobrinho, A. G., Purchas, R. W. Kadim, I. T. \& Yamamoto, S. M. (2005). Características de qualidade da carne de ovinos de diferentes genótipos e idades ao abate. Revista Brasileira de Zootecnia, 34: 1070-1078.

Simões, J. A. \& Ricardo, R. (2000). Avaliação da cor da carne tomando como referência o músculo rectus abdominis, em carcaças de cordeiros leves. Revista Portuguesa de Ciências Veterinárias, 95: 124-127.

Valero, M. V., Torrecilhas, J. A., Zawadzki, F., Bonafé, E. G., Madrona, G. S., Prado R. M., Passette, R. A. C., Rivaroli, D. C., Visentainer, J. V. \& Prado, I. N. (2014). Propolis or cashew and castor oils effects on composition of Longissimus muscle of crossbred bulls finished in feedlot. Chilean Journal of Agricultural Research, 74: 445451.

Venturini, K. S., Sarcinelli, M. F. \& Silva. L. (2007). Características da carne de frango. Universidade Federal do Espírito Santo, Vitória.

Verbeke, W., Marcu, A., Rutsaert, P., Gaspar, R., Seibt, B., Fletcher D. \& Barnett, J. (2015). Would you eat cultured meat?: Consumers' reactions and attitude formation in Belgium, Portugal and the United Kingdom. Meat Science, 102: 49-58.

Vergara, H. \& Gallego, L. (2000). Effect of electrical stunning on meat quality of lamb. Meat Science, 56: 345-349.

Vergara, H., Linares, M. B., Berruga, M. I. \& Gallego, L. (2005). Meat quality in suckling lambs: effect of pre-slaughter handling. Meat Science, 69: 473-478.

Vestergaard, M., Oksbjerg, N. \& Henckel, P. (2000). Influence of feeding intensity, grazing and finishing feeding on muscle fibre characteristics and meat colour of (semitendinosus, longissimus dorsi) and (supraspinatus) muscles of young bulls. Meat Science, 54: 177-185.

Warriss, P. D. (1990). The handling of cattle preslaughter and its effects on carcass and meat quality. Appl. Anim. Behav. Sci.28: 171-186.
Watanabe, A., Daly, C. C. \& Devine, C. E. (1996). The effects of the ultimate $\mathrm{pH}$ of meat on tenderness changes during ageing. Meat Science, 42: 67-78.

Webb, E. C., Casey, N. H. \& Simela, L. (2005). Goat meat quality. Small Ruminant Res. 60: 153-166.

Webb, E. C., \& O'Neill, H. A. (2008). The animal fat paradox and meat quality. Meat Science, 80: 28-36.

Wheeler, T. L., Shackelford, S. D., Johnson, L. P., Miller, M. F., Miller, R. K. \& Koohmaraie, M. (1997). A comparison of Warner-Bratzler shear force assessment within and among institutions. Journal Animal Science, 75: 2423-2432.

Wood, J. D., Enser, M., Fisher, A. V., Nute, G. R., Sheard, P. R., Richardson R. I., Hughes, S. I. \& Whittington, F.M. (2008). Fat deposition, fatty acid composition and meat quality: A review. Meat Science, 78: 343-358.

Wood, J. D., Enser, M., Fisher, A. V., Nute, G. R., Whittington, F. M. \& Richardson, R. I. (2003). Effects of diets on fatty acids and meat quality. Options Méditerranéennes, Series A 67: 133-141.

Wood, J. D., R. I. Richardson, G. R. Nute, A. V. Fisher, M. M. Campo, E. Kasapidou et al. (2004). Effects of fatty acids on meat quality: a review. Meat Science, 66: 21-32.

Zapata, J. F. F., C. M. Nogueira, L. M. J. Seabra, N. R. Barros, \& A. S. Borges. (2001). Composição centesimal e lipídica da carne de ovinos do nordeste brasileiro. Ciência Rural 31: 691-695.

Zawadski, F., Valero, M. V. \& Prado, I. N. (2010). Uso de aditivos na dieta de bovinos de corte. In: I. N. Prado (ed.) Produção de bovinos de corte e qualidade da carne No. 1. p 149-178. Eduem, Maringá, Paraná, Brasil.

Zawadzki, F., Prado, I. N., Marques, J. A., Zeoula, L. M., Prado, R. M., Fugita C. A., Valero, M. V. \& Maggioni, D. (2011 $)$. Sodium monensin or propolis extract in the diet of Nellore bulls finished in feedlot: chemical composition and fatty acid profile of Longissimus muscle. Semina: Ciências. Agrárias, 32: 1627-1636.

Zawadzki, F., Prado, I. N., Marques, J. A., Zeoula, L. M., Rotta, P. P., Sestari, B. B. \& 
Rivaroli, D. C. (2011b). Sodium monensin or propolis extract in the diets of feedlot-finished bulls: effects on animal performance and carcass characteristics. Journal Animal Feed Science, 20: 16-25.

Zeola, N. M. B., Silva Sobrinho, A. G., Gonzaga Neto, S. \& Marques, C. A. T. (2004). Composição centesimal da carne de cordeiros submetidos a dietas com diferentes teores de concentrado. Ciencia Rural, 34: 253-257.
Zeola, N. M. B. L., \& Silva Sobrinho, A. G. (2001). Composição química da carne ovina. Revista Nacional da Carne, 25: 36-48.

Recebido em Novembro 20, 2015

Aceito em Janeiro 4, 2016

License information: This is an open-access article distributed under the terms of the Creative Commons Attribution License, which permits unrestricted use, distribution, and reproduction in any medium, provided the original work is properly cited. 